\title{
Left main bronchus sleeve resection with reconstruction of neolobar carina
}

Claudio Caviezel, MD, Friederike Koersgen, MD, Walter Weder, MD, and Ilhan Inci, MD, Zurich,

Switzerland

From the Division of Thoracic Surgery, University Hospital Zurich, Zurich, Switzerland.

Disclosures: Authors have nothing to disclose with regard to commercial support.

Received for publication Nov 2, 2016; revisions received Dec 21, 2016; accepted for publication Feb 19, 2017; available ahead of print April 1, 2017

Address for reprints: Ilhan Inci, MD, Division of Thoracic Surgery, University Hospital Zurich, Raemistrasse 100, Zurich 8091, Switzerland (E-mail: ilhan.inci@usz.ch).

J Thorac Cardiovasc Surg 2017;154:370-2

$0022-5223 / \$ 36.00$

Copyright $(c) 2017$ by The American Association for Thoracic Surgery

http://dx.doi.org/10.1016/j.jtcvs.2017.02.060

Video clip is available online.

The mainstay of treatment of pulmonary carcinoid tumors is surgical resection. ${ }^{1}$ Excellent long-term survival is especially seen for typical carcinoids. ${ }^{2}$ Endobronchial carcinoids often have a small base infiltrating the bronchial wall. They rarely grow beyond the confines of the bronchus. Typical locations for isolated bronchial sleeve resections are both main stem bronchi, the right intermediate bronchus, and the lobar carina. ${ }^{3}$ Isolated resection of the left lobar carina seems to be the most challenging sleeve resection among thoracic surgical procedures because pulmonary hilar vessels limit the optimal exposure. Operative technique has not been described in detail in the literature, especially concerning the anterior hilar approach.

\section{TECHNIQUE}

A 38-year-old man with a typical carcinoid TNM staging of cT1a cN0 cM0 located on the left lobar carina was referred to our institution for surgery. On radiograph, the tumor appeared to grow on the left lower lobe but preoperative bronchoscopy located it at the lobar carina (Figure 1). General anesthesia with a right-sided double-lumen tube was initiated and we performed a left anterolateral thoracotomy in the fourth intercostal space. Feasibility of an isolated bronchial sleeve resection was determined intraoperatively. The upper and lower pulmonary veins and the main trunk of the pulmonary artery were encircled with vessel loops. The main bronchus and the lobar bronchi were dissected ventrally (Figure 2, A). The pulmonary artery was dissected in the fissure, which is a very important step. The fissure was divided by stapler. An anterior approach was used to

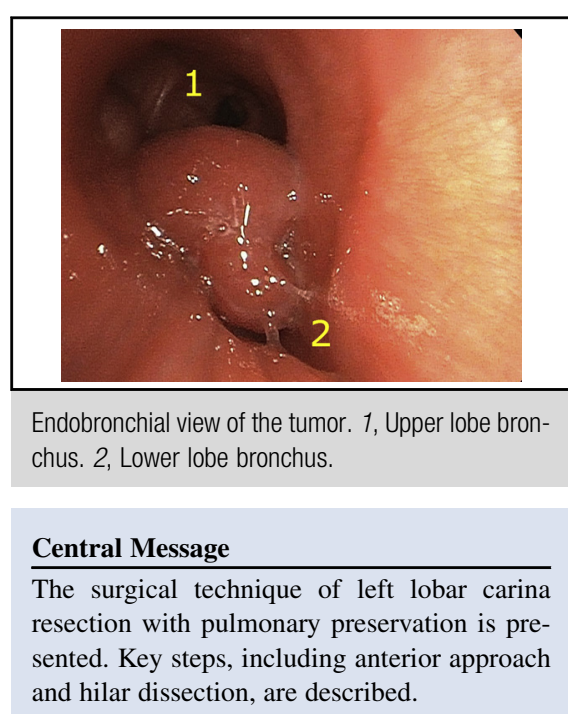

See Editorial Commentary page 373.

facilitate safe encirclement of both lobar bronchi (Figure 2, B) and allowed more space. Needle puncture of the bronchial wall under bronchoscopic view determined the resection margins. After bronchial resection, stay sutures were placed at the junctions between the membranous and the cartilagenous wall of the proximal and distal bronchial ends. The upper lobe bronchus was

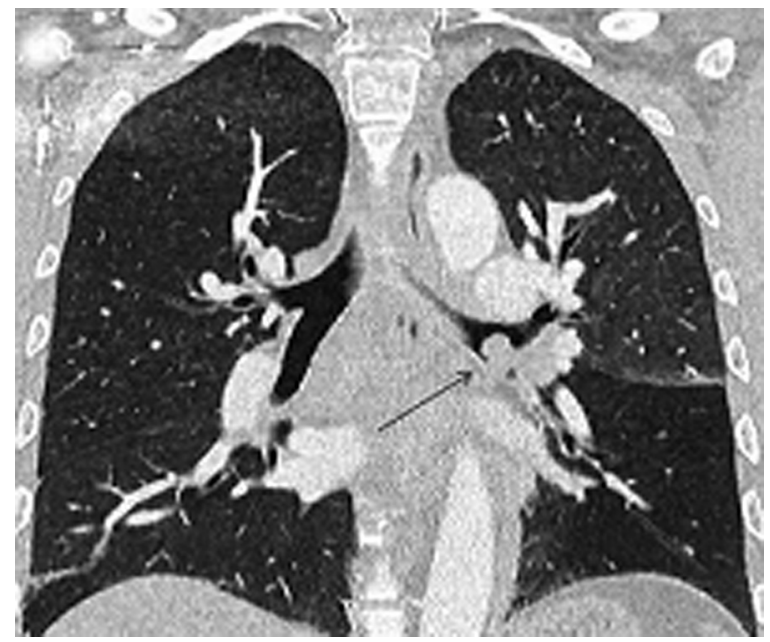

FIGURE 1. Axial computed tomography scan. The arrow marks the tumor. 
resected just proximal to the lingula bronchus and the lower lobe bronchus was cut just proximal to the segment- 6 bronchus (Figure 2, B). Because the tumor tended to grow at the cartilagenous wall of the bronchi, a small posterior membranous bridge between the main bronchus and the medial upper lobe bronchus was preserved (Figure 2,C). This step was achieved because the bronchial resection began ventrally and exact endobronchial anatomy was known. This bridge helped in further anatomic reconstruction. Anastomosis was performed with polydioxanone 4-0 running sutures for the membranous wall and with interrupted sutures for the cartilagenous wall of the bronchus (Figure 2,D). Further covering was not performed. Mediastinal lymph node dissection (stations 5, 6, 7, 8L, and 9L) was performed, whereas hilar stations $(10 \mathrm{~L}, 11 \mathrm{~L}$, and $12 \mathrm{~L})$ had been extracted during dissection of the bronchi. Intraoperative frozen section revealed negative resection margins. Reventilation revealed a prompt lung expansion and intraoperative bronchoscopy showed the neocarina with open bronchi to all segments. Insertion of 1 chest tube and chest closure completed the operation.

The postoperative course was uneventful and the patient was dismissed after 4 days. Outpatient bronchoscopy 4 weeks postoperatively showed an open and well-healed anastomosis (Video 1).

\section{COMMENT}

Bronchial sleeve resections with pulmonary preservation for carcinoid tumors and other low-grade malignant tumors have widely been demonstrated. ${ }^{4,5}$ There are very few detailed reports regarding parenchyma sparing resections

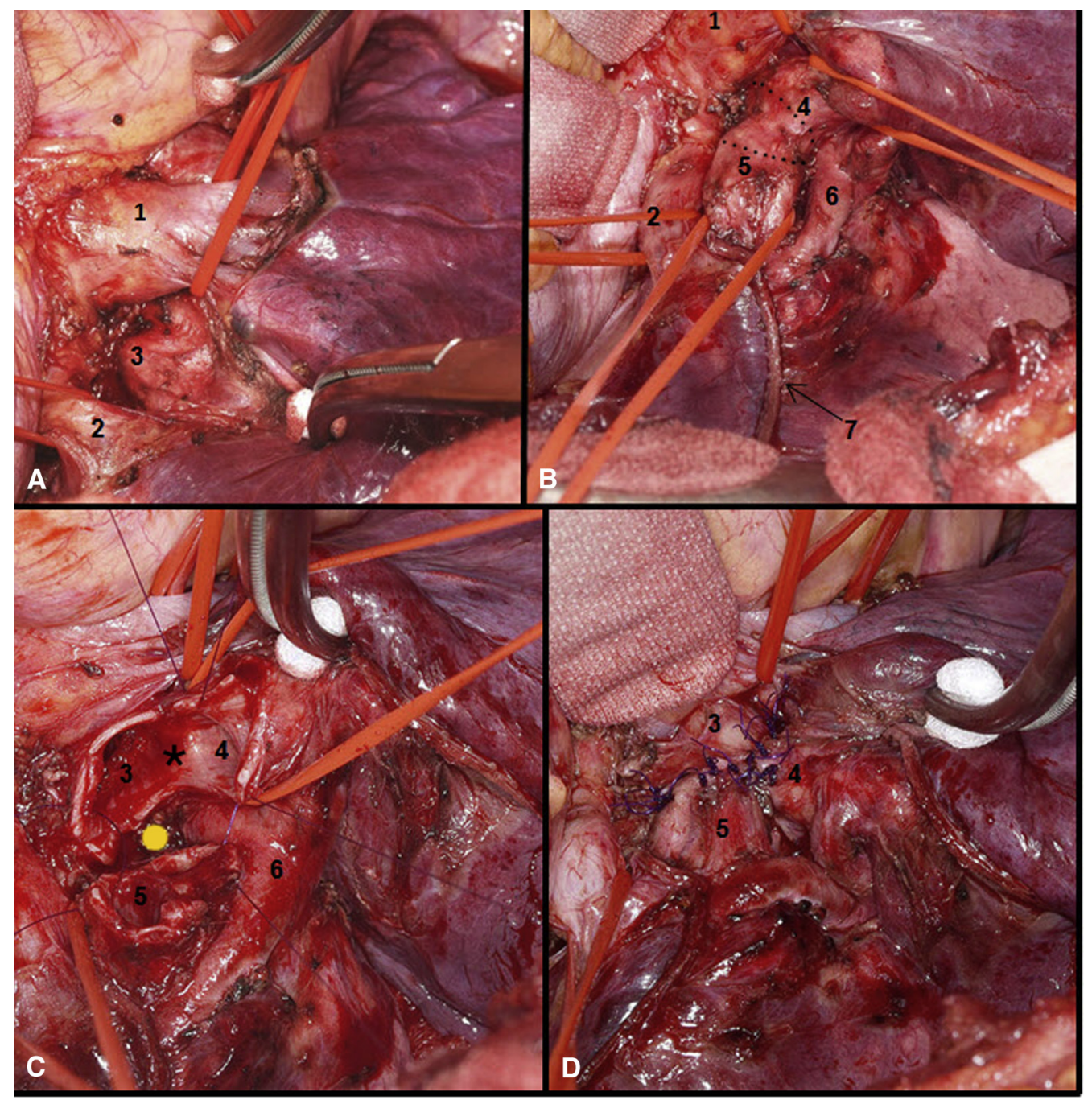

FIGURE 2. A-D, Ventral dissection, tumor resection, and anastomosis are shown: The small black dots indicate the resection line, whereas the large yellow dot indicates former tumor at the posterior bronchial wall. 1, Upper lobe vein; 2, lower lobe vein; 3, main bronchus; 4, upper lobe bronchus; 5, lower lobe bronchus; 6 , pulmonary artery; 7 , divided fissure. *Posterior bridge between left main bronchus and left upper bronchus. 


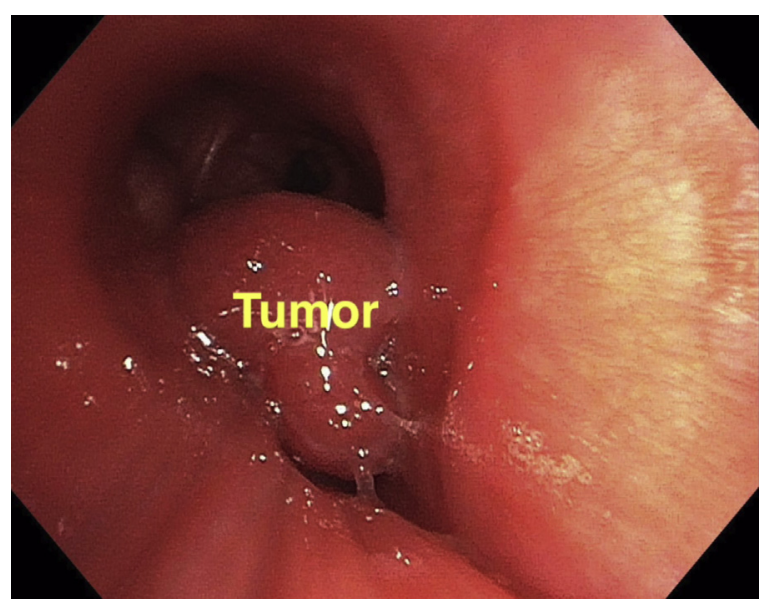

VIDEO 1. The video describes the preoperative and postoperative bronchoscopy and computed tomography scans and also includes the intraoperative pictures featuring the sleeve resection. Video available at: http://www.jtcvsonline. org/article/S0022-5223(17)30422-1/addons.

of tumors on the left lobar carina. They either describe techniques via posterolateral thoracotomy or do not focus on the hilar approach and the vascular dissection. ${ }^{4}$ Our technique permits a safe and effective anterior approach. The key steps include encircling of all surrounding pulmonary vessels and the bronchi and dividing the fissure. Accurate anatomic features of the tumor must be known and double-checked with intraoperative bronchoscopy to allow accurate bronchial resection. Alternatively, a lower lobe sleeve lobectomy could be performed, which in this case was the fallback plan. The tumor grew on the lobar carina but was slightly closer to the cartilagenous part of the left lower bronchus. Uramoto and colleagues ${ }^{6}$ report a similar case but describe an upper lobe tumor also involving the left main bronchus and segment 8 bronchus. A left upper lobe double sleeve lobectomy was performed with creation of a new carina for segment 6 and the basal segments. Cases of tumors simultaneously involving the upper and the lower lobe bronchus sometimes require that a pneumonectomy is performed.

\section{CONCLUSIONS}

This technique is feasible, but it should be reserved for tumors not growing beyond the confines of the bronchus. Patients benefit from parenchyma-sparing resections, and therefore planning isolated bronchial resection should be undertaken even for left lobar carina tumors.

The authors thank Helen Mueller-McKenna for providing manuscript editing.

\section{References}

1. Garcia-Yuste M, Matilla JM, Cueto A, Paniagua JM, Ramos G, Canizares MA, et al. Typical and atypical carcinoid tumours: analysis of the experience of the Spanish Multi-centric Study of Neuroendocrine Tumours of the Lung. Eur J Cardiothorac Surg. 2007;31:192-7.

2. Rea F, Rizzardi G, Zuin A, Marulli G, Nictra S, Bulf R, et al. Outcome and surgical strategy in bronchial carcinoid tumors: single institution experience with 252 patients. Eur J Cardiothorac Surg. 2007;31:186-91.

3. Hoffmann H. Bronchial sleeve resections. In: Chest surgery. Springer Surgery Atlas Series. New York: Springer; 2015.

4. Lucchi M, Melfi F, Ribechini A, Dini P, Duranti L, Fontanini G, et al. Sleeve and wedge parenchyma-sparing bronchial resections in low-grade neoplasms of the bronchial airway. J Thorac Cardiovasc Surg. 2007;134:373-7.

5. Cerfolio RJ, Deschamps C, Allen MS, Trastek VF, Pairolero PC. Mainstem bronchial sleeve resection with pulmonary preservation. Ann Thorac Surg. 1996;61: $1458-62$.

6. Uramoto H, Nakajima Y, Kinoshita H. Left upper lobe double sleeve lobectomy with double barrel anastomosis for lung adenocarcinoma. Ann Med Surg (Lond). 2016;9:12-4. 